\title{
Complementary Methods for the Characterization of Corrosion Products on a Plant- Exposed Superheater Tube
}

Okoro, Sunday Chukwudi; Nießen, Frank; Villa, Matteo; Apel, Daniel; Montgomery, Melanie; Jappe Frandsen, Flemming; Pantleon, Karen

Published in:

Metallography, Microstructure, and Analysis

Link to article, DOI:

$10.1007 / \mathrm{s} 13632-016-0325-6$

Publication date:

2017

Document Version

Peer reviewed version

Link back to DTU Orbit

Citation (APA):

Okoro, S. C., Nießen, F., Villa, M., Apel, D., Montgomery, M., Jappe Frandsen, F., \& Pantleon, K. (2017). Complementary Methods for the Characterization of Corrosion Products on a Plant-Exposed Superheater Tube. Metallography, Microstructure, and Analysis, 6(1), 22-35. https://doi.org/10.1007/s13632-016-0325-6

\section{General rights}

Copyright and moral rights for the publications made accessible in the public portal are retained by the authors and/or other copyright owners and it is a condition of accessing publications that users recognise and abide by the legal requirements associated with these rights.

- Users may download and print one copy of any publication from the public portal for the purpose of private study or research.

- You may not further distribute the material or use it for any profit-making activity or commercial gain

- You may freely distribute the URL identifying the publication in the public portal 


\title{
Complementary methods for characterization of corrosion products on a plant exposed superheater tube
}

Sunday Chukwudi Okoro, ${ }^{1, *}$, Frank Nießen ${ }^{2}$, Matteo Villa ${ }^{1}$, Daniel Apel ${ }^{3}$, Melanie Montgomery ${ }^{1}$, Flemming Jappe Frandsen ${ }^{4}$, Karen Pantleon ${ }^{1}$.

${ }^{1}$ Department of Mechanical Engineering, Technical University of Denmark (DTU), 2800 Kongens Lyngby, Denmark.

${ }^{2}$ The Danish Hydrocarbon Research and Technology Centre, DTU, 2800 Kongens Lyngby, Denmark.

${ }^{3}$ Helmholtz-Zentrum Berlin für Materialien und Energie, 12489 Berlin, Germany.

${ }^{4}$ CHEC Research Centre, Department of Chemical and Biochemical Engineering, DTU, 2800 Kongens Lyngby, Denmark.

* Phone: +45 50185680, Fax: +45 45936213, Email: sunoko@mek.dtu.dk, okorochukwudi@ymail.com

\begin{abstract}
In this work, complex corrosion products on a superheater tube exposed to biomass-firing were characterized by the complementary use of energy-dispersive synchrotron diffraction, electron microscopy and energy-dispersive X-ray spectroscopy. Non-destructive synchrotron diffraction in transmission geometry measuring with a small gauge volume from the sample surface through the corrosion product, allowed depth-resolved phase identification and revealed the presence of $(\mathrm{Fe}, \mathrm{Cr})_{2} \mathrm{O}_{3}$ and $\mathrm{FeCr}_{2} \mathrm{O}_{4}$. This was supplemented by microstructural and elemental analysis correlating the additional presence of a Ni-rich-austenite phase to selective removal of $\mathrm{Fe}$ and $\mathrm{Cr}$ from the alloy, via a KCl-induced corrosion mechanism. Compositional variations were related to diffraction results and revealed a qualitative influence of the spinel cation-concentration on the observed diffraction lines.
\end{abstract}

Keywords: Stainless steel; (Synchrotron) X-ray diffraction; SEM; High temperature corrosion; Chlorination; Spinel.

\section{Introduction}

Although combustion of biomass provides a ' $\mathrm{CO}_{2}$ neutral' means of energy generation, this fuel gives operational challenges during combustion in power plants [1-3]. The high alkali chloride content in biomass causes fast corrosion of superheaters due to the formation of corrosive deposits (rich in $\mathrm{KCl}$ ) 
as well as the presence of corrosive species in the flue gas ( $\mathrm{HCl}, \mathrm{SO}_{2}$, etc.) [4-7]. In particular, operation at lower steam temperatures $\left(\sim 540{ }^{\circ} \mathrm{C}\right)$ to control the rate of corrosion limits the electrical efficiency of biomass-fired power plants [8]. The development of corrosion resistant alloys and coatings relies on detailed understanding of the underlying corrosion mechanisms. For corrosion under biomass firing (i.e. alkali chloride containing) conditions, a comprehensive characterization of corrosion products is among the prerequisites for understanding the associated high temperature corrosion mechanisms.

Corrosion products resulting from exposure to alkali chlorides in power plants are often heterogeneous and may be up to several hundreds of micrometres thick. Thus, the use of conventional characterization techniques is not straightforward. In addition, the solubility of some of the corrosion products in water-based lubricants raises challenges during sample preparation prior to characterization. Laboratory exposures studying the influence of specific parameters on corrosion of samples with simplified geometries have successfully used advanced characterization techniques (for example, transmission electron microscopy [9], auger electron spectroscopy [10], chronoamperometry [11], etc.) to characterize corrosion products or monitor their formation in-situ [12]. Such advanced techniques are difficult to use for plant exposed samples not only because of the complex morphology of corrosion products originating from real plant exposure but also due to challenging sample geometries.

Some studies have attempted to characterize the corrosion products on plant exposed test superheaters or probes [8,13-18]. In these studies, the complex morphology of corrosion products restricted the characterization to light optical and scanning electron microscopy as well as energy dispersive X-ray spectroscopy, mostly carried out on cross sections of samples. Although X-ray diffraction strongly supplements microscopy and elemental analysis, only few studies have attempted to identify the crystalline corrosion product phases on real superheater tubes by this technique. The low penetration depth (several micrometres only) of the employed conventional X-ray sources in such studies limited the analysis to the very near surface region of the corrosion products thereby detecting mostly $\mathrm{KCl}$ and $\mathrm{K}_{2} \mathrm{SO}_{4}[13,14]$ and prevented detailed phase analysis of the fairly thick corrosion products.

It has recently been demonstrated by some of the present authors that complex corrosion products resulting from laboratory exposure mimicking that in biomass-fired power plants, can be comprehensively characterized by the complementary use of scanning electron microscopy, energy dispersive X-ray spectroscopy and X-ray diffraction with conventional X-ray sources in combination with successive layer removal [19]. Though time consuming, the reported top-down plan view method revealed results that aided understanding of the deposit-gas interactions as well as the role of chlorination and sulphidation as corrosion mechanisms. Aiming for a methodology for comprehensive characterization of corrosion products on real superheater tubes exposed to biomass firing in power plants, the present work demonstrates the capability of using energy-dispersive synchrotron diffraction in transmission geometry for non-destructive depth profiling of complex and bulky corrosion products on a plant exposed superheater tube. The results were complemented with 
scanning electron microscopy and energy dispersive X-ray spectroscopy and contribute to understanding of the corrosion mechanisms on samples obtained from a biomass firing power plant.

2.

Experimental

2.1.

Sample history

The investigated sample originated from a superheater loop in a biomass suspension fired $350 \mathrm{MW}_{\text {th }}$ - boiler (Amager Power Station, Unit 1) located in Denmark. The superheater had been operated for 30534 hours. During this period the outlet steam temperature was approx. $540{ }^{\circ} \mathrm{C}$ and the fuel used was straw and wood pellets. The superheater has an outer diameter of $38 \mathrm{~mm}$ and a wall thickness of $6.3 \mathrm{~mm}$. It consists of austenitic stainless steel TP $347 \mathrm{H}$ in a fine-grained version (FG), which is one of the commercially applied materials. The chemical composition is given in Table 1.

Table 1. Chemical composition (in wt. \%) of TP 347H FG determined by energy dispersive X-ray spectroscopy. A fusion thermal conductivity unit LECO CS230 was used for the measurement of the carbon content [20].

\begin{tabular}{lllllll}
\hline Fe & Si & Mn & Cr & Ni & Nb & C \\
\hline Bal. & 0.4 & 2.0 & 18.2 & 10.1 & 0.6 & 0.057
\end{tabular}

A ring of the exposed superheater was cut with a saw from longer tube sections under dry conditions. This was then 'cold-embedded' in epoxy under vacuum to avoid spallation of corrosion product layers during experimental investigations and sample handling. By means of grinding under water-free conditions (using absolute ethanol, 99.9\%, as lubricant) to reduce removal of water soluble phases of the corrosion products, the thickness of the embedded ring was reduced to $3 \mathrm{~mm}$.

\subsection{Depth-resolved energy-dispersive synchrotron diffraction}

\subsubsection{Experimental setup of diffraction measurements}

Depth profiling of the corrosion products by diffraction applying synchrotron radiation was carried out at the Energy Dispersive Diffraction (EDDI) materials science beamline at the Berlin synchrotron storage ring (BESSY II). The sample investigated was a $3 \mathrm{~mm}$ thick ring obtained from the exposed superheater tube as described in section 2.1.

Unlike the angle-dispersive diffraction mode, the energy-dispersive diffraction is carried out at a fixed diffraction angle and generates a multitude of diffraction lines during one measurement at fixed diffraction angle [21]. For the present study, the diffraction angle was set to $2 \theta=6^{\circ}$. A snapshot of the diffractometer setup applied for depth profiling is shown in Figure 1a and schematically illustrated in Figure 1b. 

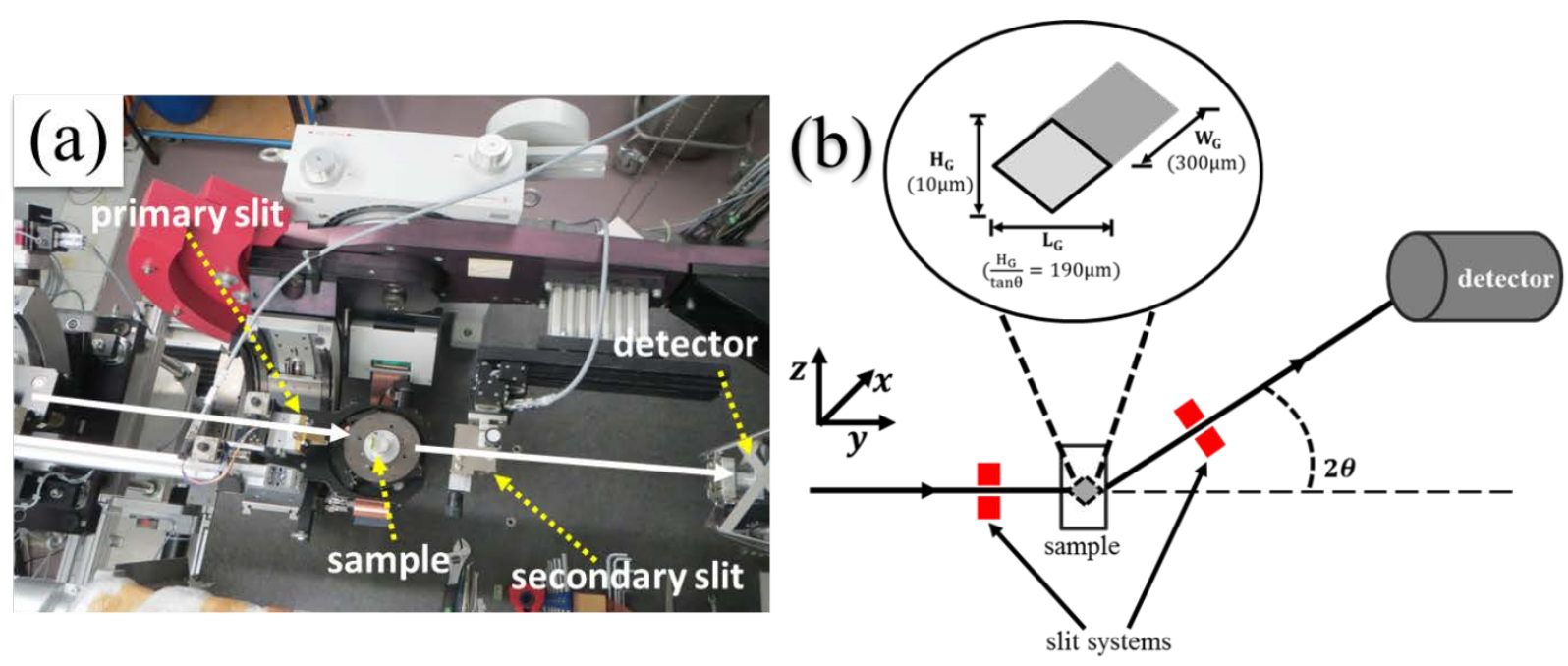

Figure 1. Snapshot (a) and schematic illustration (b) of the setup applied for depth profiling by means of energy-dispersive synchrotron diffraction at the EDDI beamline, BESSY II.

The highly brilliant and high intense synchrotron radiation enables measurements in transmission geometry through the $3 \mathrm{~mm}$ thick sample of the present study, and it further allows the use of small gauge volumes, resulting in good spatial resolution [22]. The gauge volume was defined by additional narrow slit systems in the primary and secondary beam paths as shown in Figure 1b (for details, see [21,23-25]). The dimensions of these slits in the axial and equatorial direction were $10 \mu \mathrm{m}$ and 300 $\mu \mathrm{m}$, respectively.

Unique depth-resolution was achieved by defined z-translations of the sample relative to the gauge volume in step sizes of $4 \mu \mathrm{m}$. As the gauge volume height of $10 \mu \mathrm{m}$ is larger than each single sample displacement, successively recorded energy-dispersive diffraction spectra partly cover the same sample regions. As a result, each measurement was assigned its corresponding depth as the sliding average over the $4 \mu \mathrm{m}$ of sample displacement.

At each sample position z, energy-dispersive diffraction spectra covering the range of up to $120 \mathrm{keV}$ were measured with an acquisition time of $150 \mathrm{~s}$ per displacement step, thus, per spectra recorded at a specific depth. Subsequent analysis considered diffraction lines between 20-85 keV which covers the most efficient photon flux in energy-dispersive experiments at EDDI [21]. Starting at the surface (defined by the first diffraction signal from the sample), depth-resolved measurements were carried out through the entire corrosion product until the original bulk alloy was reached. This measurement procedure was applied on two locations along the sample ring (tube): on the windward side (so-called position 12 o'clock) of the tube and on a position located $270{ }^{\circ}$ from the windward side (position 9 o’clock). These positions are schematically illustrated in Figure 2. 


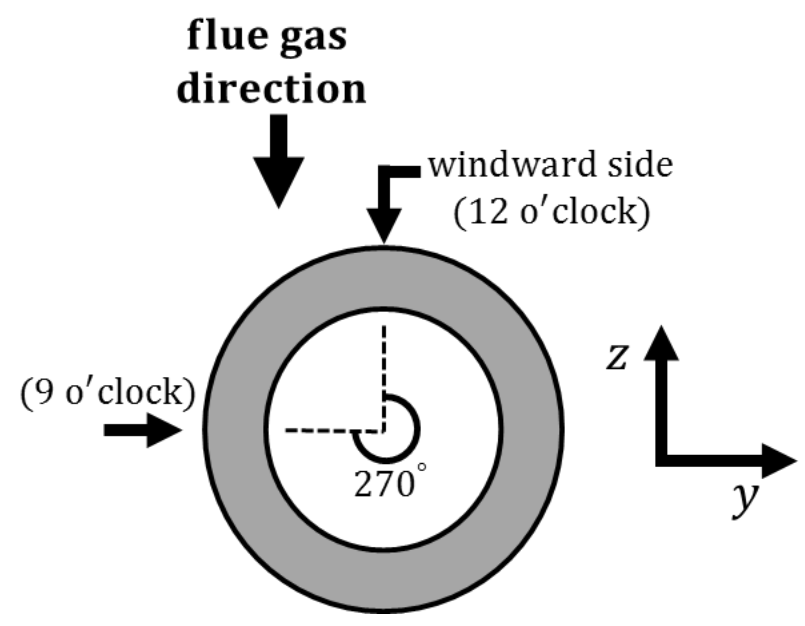

Figure 2. Schematic illustration of the tube circumference showing positions on which investigations were carried out.

\subsubsection{Analysis of the measured energy-dispersive diffraction spectra}

With the aforementioned procedure for non-destructive depth-resolved energy-dispersive synchrotron diffraction analysis of the corrosion product on different locations of the superheater tube, hundreds of diffraction spectra were measured subsequently as a function of depth. The recorded spectra were evaluated using an analysis procedure programmed in MATLAB and provided by the EDDI beamline scientists. Prior to peak profile fitting, the measured diffraction profiles were corrected for instrumental effects, which implied corrections of the Wiggler spectrum, dead time correction and intensity corrections according to slight changes of the ring current during the measurements. Absorption correction was applied for Fe as the main absorbing component, whereas an absorption correction for each individual phase was not applied due to obvious changes of the phase fractions within the corrosion product. The measurement of a reference sample consisting of $\mathrm{Au}$ powder revealed an excellent alignment status of the diffractometer, thus, no additional instrumental correction of the diffraction line positions was necessary.

The background was subtracted by manual assignment of the background positions for each diffraction line in the spectra. Diffraction peaks were fitted using a pseudo-Voigt profile function, which provided the position $\mathrm{E}^{\mathrm{hkl}}$ of all diffraction lines hkl in the various spectra. The respective lattice planar spacings $\mathrm{d}^{\mathrm{hkl}}$ were calculated according to

$$
\mathrm{d}^{\mathrm{hkl}}=\frac{\mathrm{hc}}{2 \sin \theta} \frac{1}{\mathrm{E}^{\mathrm{hkl}}}
$$

( $h$ is the Plank's constant, $c$ is the speed of light and $\theta$ corresponds to half of the applied constant diffraction angle) [26], which allowed qualitative phase analysis throughout the corrosion product.

\subsection{Electron microscopy and energy dispersive X-ray spectroscopy}

In addition to depth profiling by means of energy-dispersive synchrotron diffraction, Scanning Electron Microscopy (SEM) analysis was carried out on the same positions along the superheater 
circumference where depth profiling by diffraction was done. Gamma ray irradiation indicator labels were used to keep track of the positions where depth profiling was undertaken and at exactly these positions on the sample's cross section, the microstructure of corrosion products was investigated with a backscatter electron detector in a SEM (Quanta ESEM FEG, FEI) using an acceleration voltage of $15 \mathrm{keV}$. Prior to SEM investigations, the sample was coated with carbon.

An energy dispersive X-ray spectrometer (Oxford instruments, $80 \mathrm{~mm}^{2}$, X-Max, SDD) attached to the SEM was used for chemical analysis of the corrosion products. Energy dispersive X-ray spectroscopy (EDS) analysis was carried out with an acceleration voltage of $15 \mathrm{keV}$. Analysis involved both elemental mapping and elemental re-quantification from the acquired maps using the Aztec and INCA software (Oxford instruments), respectively. The elemental re-quantification involved division of investigated cross sections into $10 \mu \mathrm{m}$ thick meshes along the direction parallel to the surface of the corrosion product (the y-coordinate), as shown in Figure 3. The length of these meshes corresponds to the full length of the investigated micrograph, which amounts to several hundreds of micrometers. At $10 \mu \mathrm{m}$ equidistant positions ( $i$ ) along the direction perpendicular to the surface of the corrosion product (the z-coordinate), the average concentration of an element, $\overline{\mathrm{C}}_{\mathrm{z}_{i}}$, is re-quantified from the corresponding strip of the mesh. $\overline{\mathrm{C}}_{\mathrm{z}_{i}}$ is plotted as a function of distance along the $\mathrm{z}$-coordinate to obtain a reliable 1-dimensional profile of the concentration of various elements averaged over several hundreds of micrometers compared to the conventional EDS line scan and point measurement procedures, which represent local snapshots not being representative for samples with inhomogeneous elemental distribution [27].
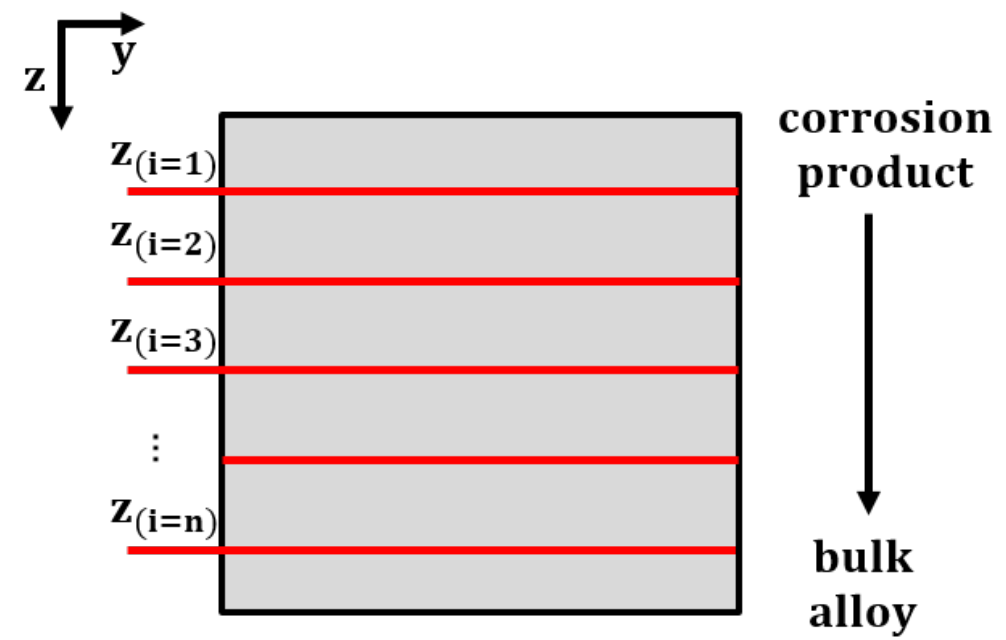

Figure 3. Schematic illustration of the division of a cross section into meshes used for requantification of elemental composition from the measured EDS maps.

3. Results

3.1. Non-destructive depth profiling with energy-dispersive synchrotron diffraction

3.1.1. Measurements on the windward side (position 12 o'clock) 
The crystalline phases present at different depths of the sample were revealed from subsequent diffraction measurements with controlled displacement (step size $=4 \mu \mathrm{m}$ ) of the sample in $\mathrm{z}$ direction. The evolution of these phases as a function of depth on the windward side (position 12 o'clock) is represented by the contour plot in Figure 4. At the near surface regions $(<150 \mu \mathrm{m})$, detected corrosion product phases comprise of (Fe,Cr) ${ }_{2} \mathrm{O}_{3}$ (designated as $\mathrm{M}_{2} \mathrm{O}_{3}$, where $\mathrm{M}=\mathrm{Fe}$ and $\mathrm{Cr}$ ), spinel $\mathrm{FeCr}_{2} \mathrm{O}_{4}$ (designated as $\mathrm{M}_{3} \mathrm{O}_{4}$, with $\mathrm{M}=\mathrm{Fe}$ and $\mathrm{Cr}$ ), $\mathrm{KCl}$ and $\mathrm{NiCl}_{2}$. The diffraction lines corresponding to the spinel phase are observed to extend deeper into the corrosion product ( $>150$ $\mu \mathrm{m})$ thereby suggesting that the corundum phase $\left((\mathrm{Fe}, \mathrm{Cr})_{2} \mathrm{O}_{3}\right)$ is predominantly located in the near surface regions while the spinel $\left(\mathrm{FeCr}_{2} \mathrm{O}_{4}\right)$ is the dominant phase in the middle of the corrosion product. Figure 4 shows that two competing austenite phases are present at different depths. Diffraction lines corresponding to a Ni-rich austenite phase (designated as $\gamma^{\mathrm{Ni}}$ ) were observed deeper in the corrosion product (from about $150 \mu \mathrm{m}$ ). These diffraction lines disappear with the emergence of diffraction lines from the austenitic stainless steel bulk (designated as $\gamma$ ) which then extends into the bulk of the alloy.

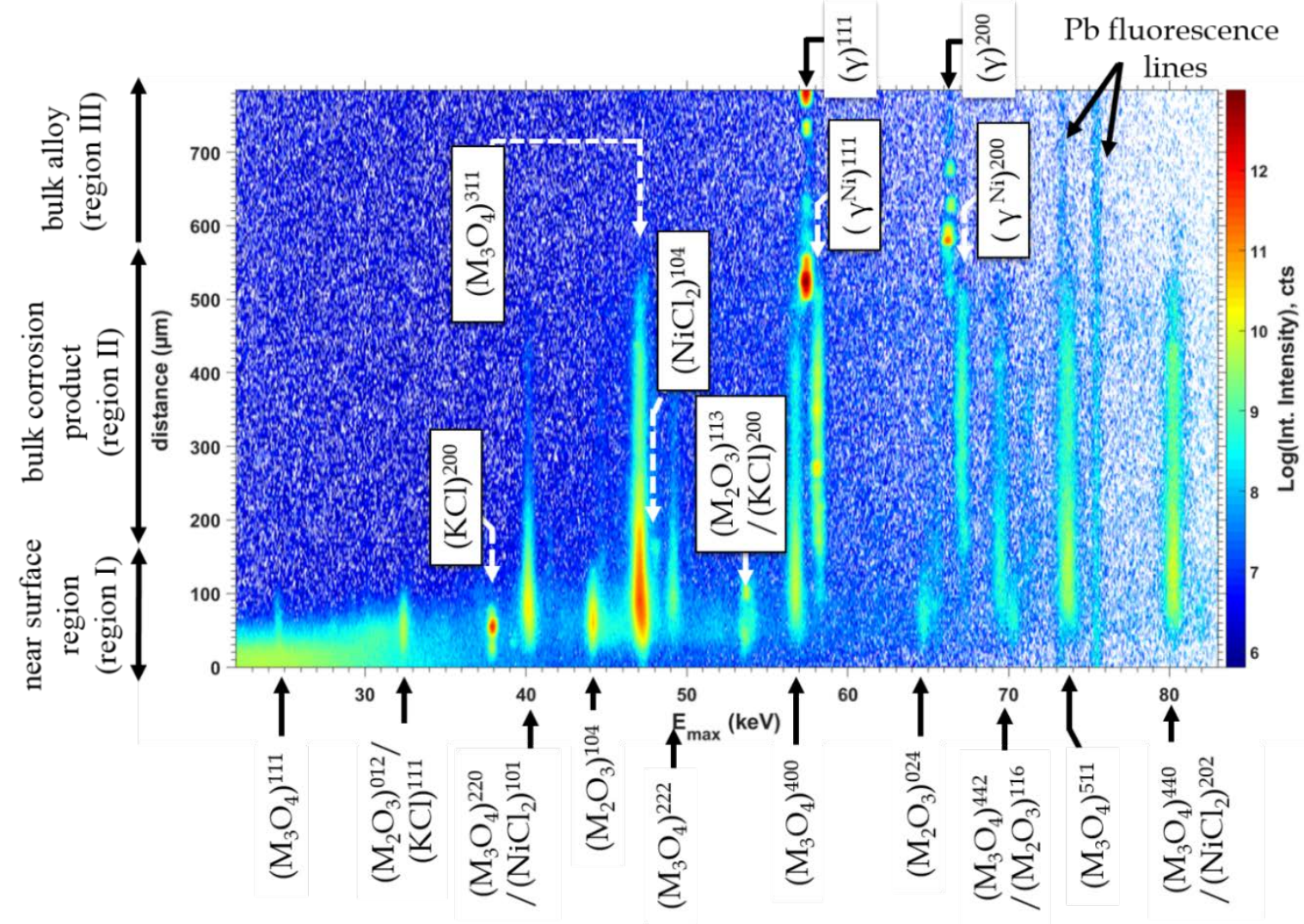

Figure 4. Phase evolution as a function of depth within the corrosion product on the windward side (position 12 o'clock). $\mathrm{M}=\mathrm{Fe}$ and $\mathrm{Cr}$ in the phases designed as $\mathrm{M}_{2} \mathrm{O}_{3}$ and $\mathrm{M}_{3} \mathrm{O}_{4}$.

In Figure 5, changes in peak positions (in the energy scale) as a function of depth are revealed for the identified phases. The near surface region, the middle of the corrosion product and the bulk alloy are denoted as regions I, II and III, respectively. A slight increase in the diffraction line position $(\Delta \mathrm{E} \sim$ $0.1 \mathrm{keV}$ ) with depth was observed for the corundum diffraction lines, in the near surface region where this phase was dominant. This is shown on the example of $\left(\mathrm{M}_{2} \mathrm{O}_{3}\right)^{012}$ in Figure 5a. Diffraction lines 
of the spinel phase shift to lower energy values with increasing depth (indicated as S1 in Figure 5b and also visible in Figure 5c). As the gauge volume was scanned from the middle of the corrosion product into the bulk alloy (from region II to III), it is observed that the $\left(\mathrm{M}_{3} \mathrm{O}_{4}\right)^{400}$ diffraction line disappears, while the $(\gamma)^{111}$ diffraction line appears. Down to approximately $250 \mu \mathrm{m}$ within the middle of the corrosion product (region II), diffraction lines corresponding to the Ni-rich austenite phase $\left(\gamma^{\mathrm{Ni}}\right)$ shifted to lower energy values $\left(\Delta \mathrm{E} \sim 0.2 \mathrm{keV}\right.$ ) (see Figure $5 \mathrm{~d}$ for the $\left(\gamma^{\mathrm{Ni}}\right)^{200}$ diffraction line). Afterwards, the position of these diffraction lines gradually shifted to higher energy values until approximately $500 \mu \mathrm{m}$, where the Ni-rich austenite disappears and only diffraction lines corresponding to the bulk alloy $(\gamma)$ were recorded and dominate within the bulk of the alloy.
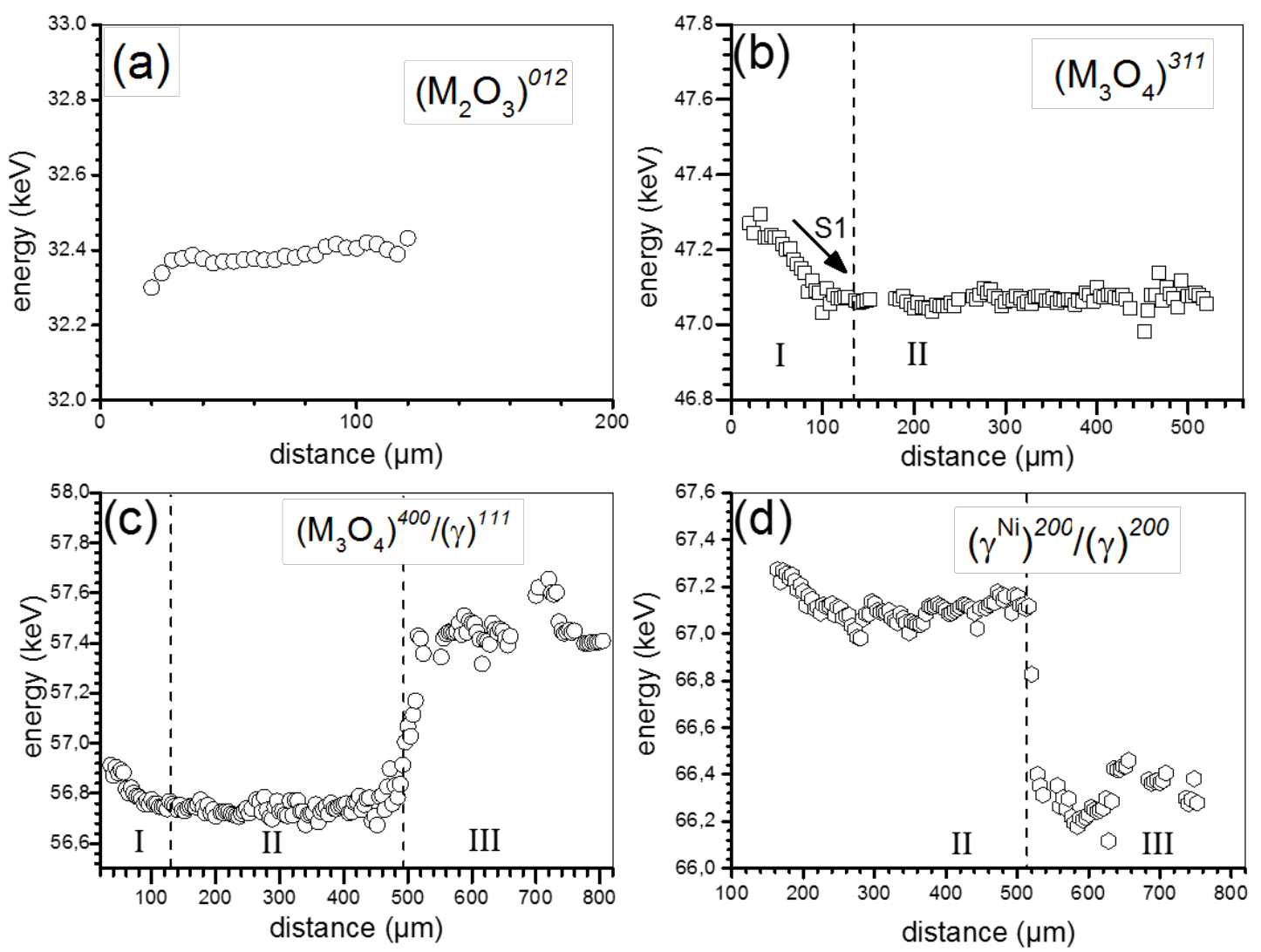

Figure 5. Evolution of the diffraction line maxima for various phases of the corrosion product observed on the windward side (position 12 o'clock). $\mathrm{M}=\mathrm{Fe}$ and $\mathrm{Cr}$ in the phases designed as $\mathrm{M}_{2} \mathrm{O}_{3}$ and $\mathrm{M}_{3} \mathrm{O}_{4}$. In (c) and (d), after approximately $500 \mu \mathrm{m}$, the $\left(\mathrm{M}_{3} \mathrm{O}_{4}\right)^{400}$ and $\left(\gamma^{\mathrm{Ni}}\right)^{200}$ diffraction lines, respectively, disappear while those of $(\gamma)^{111}$ and $(\gamma)^{200}$ appear. The regions I, II and III denote the near surface region, middle of the corrosion product and the bulk alloy, respectively.

\subsubsection{Measurements on position located $270{ }^{\circ}$ from the windward side (position 9 o'clock)}

It is expected that variations in factors such as the deposition rate, flue gas temperature, superheater configuration, etc. may cause differences in the type of corrosion products and the degree of corrosion around the tube circumference. However, results from depth profiling at position 9 o'clock (Figure 
6a) reveal the presence of the same oxide phases, but with different extension in depth compared with the corrosion products on position 12 o'clock (cf. Figures 4 and 6). At position 9 o'clock, the corundum phase $\left(\mathrm{M}_{2} \mathrm{O}_{3}\right)$ was predominant in region I of the corrosion product $(<50 \mu \mathrm{m})$, while the spinel $\left(\mathrm{M}_{3} \mathrm{O}_{4}\right)$ phase was predominant within region II of the corrosion product, and extended into region III, presumably in the form of grain boundary attack. Although distinct diffraction lines corresponding to the Ni-rich austenite phase $\left(\gamma^{\mathrm{Ni}}\right)$ were not observed on position 9 o'clock, the phase seem to be present, because it caused large asymmetries in the $(\gamma)^{111}$ and $(\gamma)^{200}$ diffraction lines due to overlap of diffraction lines for the two different austenite phases (see for example, Figure 6b).
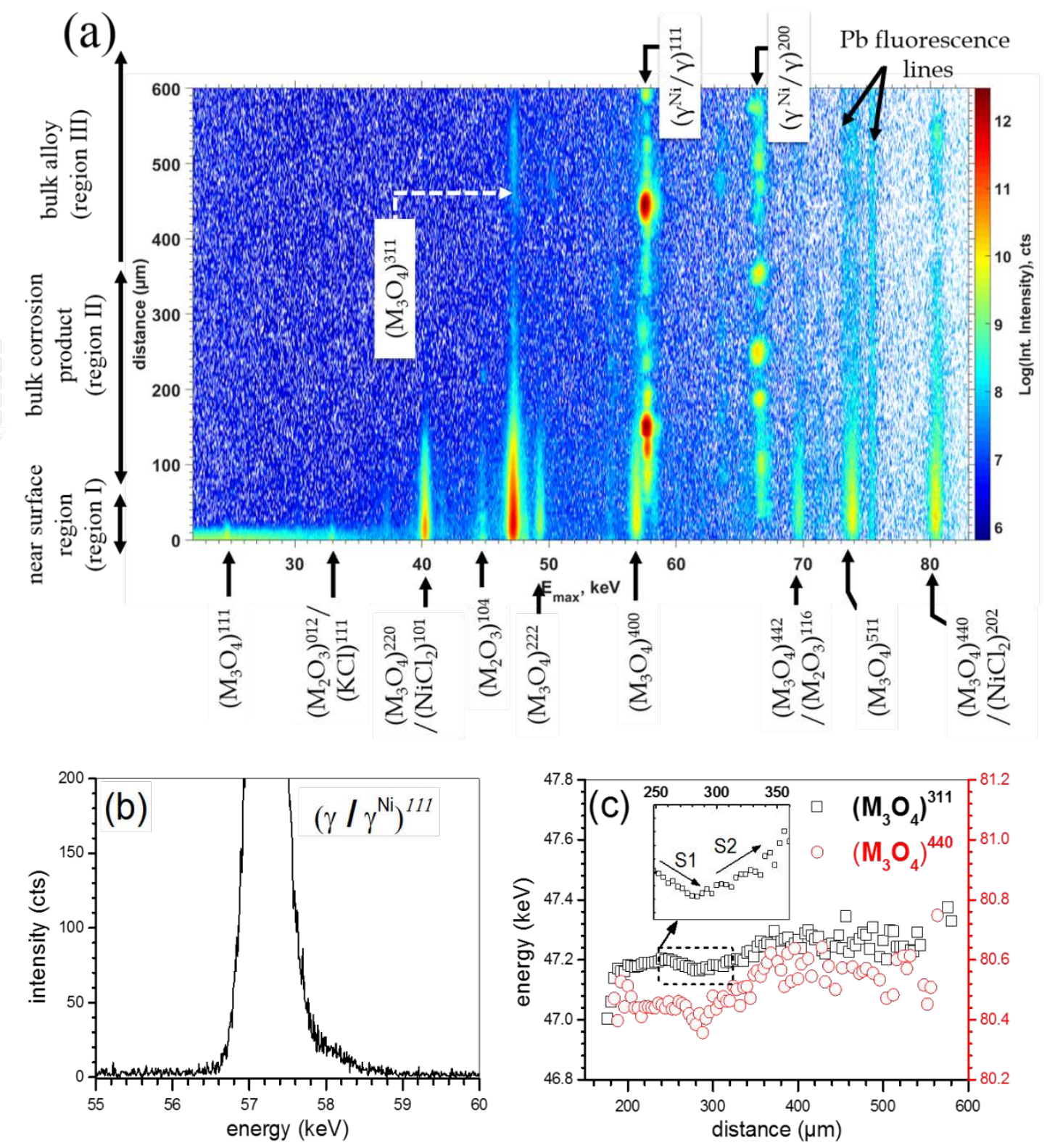

Figure 6. (a) Phase evolution as a function of depth within the corrosion product on the position located $270{ }^{\circ}$ from the windward side (position 9 o'clock). (b) Asymmetry in the $(\gamma)^{111}$ diffraction 
line as a result of overlap with the Ni-rich austenite $\left(\gamma^{\mathrm{Ni}}\right)^{111}$ diffraction line. (c) Variation in diffraction line maxima for the spinel phase $\mathrm{M}_{3} \mathrm{O}_{4} . \mathrm{M}=\mathrm{Fe}$ and $\mathrm{Cr}$ in the phases designed as $\mathrm{M}_{2} \mathrm{O}_{3}$ and $\mathrm{M}_{3} \mathrm{O}_{4}$.

Fitting of the spinel diffraction lines to a pseudo Voigt function (Figure 6c) showed that the energy position of intensity maxima of these lines varied with depth and two remarkable steps were observed. These steps are indicated as S1 and S2 in Figure 6c for both the 311 and 440 diffraction lines of $\mathrm{M}_{3} \mathrm{O}_{4}$. Both diffraction line maxima shift first to lower energy (S1), and thereafter, exhibit a shift (S2) to higher energy as the scan proceeds from the middle of the corrosion product towards the bulk alloy.

\subsection{Microscopic investigation and elemental composition of corrosion products}

\subsubsection{Microstructure of corrosion products}

Backscattered electron (BSE) imaging is excellent for the characterization of corrosion products under complex atmospheres because the contrast originates from differences in atomic number of elements in the corrosion product and, thus, gives a hint on the various phases. This is reflected in the cross-sectional BSE micrographs in Figure 7, which show the microstructure of corrosion products on position 12 o'clock of the superheater. Differences between the atomic number of elements included in the corrosion products, and the bulk alloy, are expected to result in contrast differences (Figure 7a). In this case, the bulk alloy $(\gamma)$ with a higher atomic number appears brighter compared to the corrosion product, as a result of generation of a higher fraction of backscattered electrons from this region. An approximately $300 \mu \mathrm{m}$ thick corrosion product layer extends into the bulk alloy, where selective attack of the alloy grain boundaries is visible. The corrosion product appears to have cracked in a direction parallel to the corrosion product/bulk alloy interface.

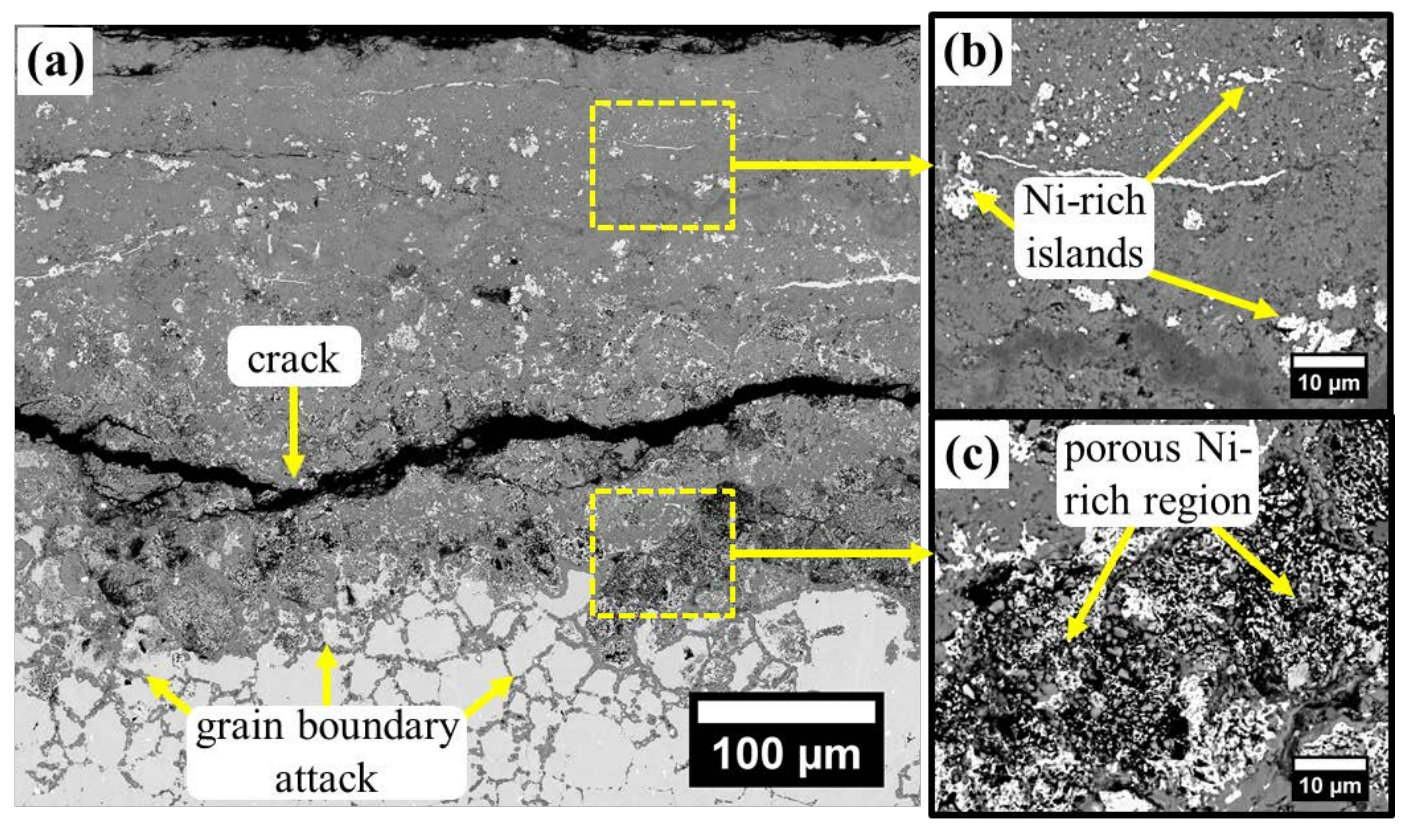

Figure 7. BSE micrographs showing: (a) an overview of the corrosion product observed on the windward side (position 12 o'clock), and (b, c): magnified images of marked regions in (a). 
Based on the resulting contrast differences in micrographs showing magnified views of the corrosion product (Figure 7b, c), a phase with a higher atomic number is revealed. This appears in the form of islands (in the near surface region, Figure $7 \mathrm{~b}$ ) and as porous regions between the middle of the corrosion product and the region of grain boundary attack (Figure 7c). This (high atomic weight) phase present in the corrosion product (i.e. the bright islands/regions) refers to the Ni-rich austenite $\left(\gamma^{\mathrm{Ni}}\right)$ phase, as was also observed from energy-dispersive synchrotron diffraction (Figure 4).

Microscopic investigations also show that the microstructure of corrosion products was qualitatively similar on different locations around the tube. Thus, the same type and morphology of phases was observed, although the overall thickness of the corrosion product appears to be different, which agrees with suggestions based on the diffraction results discussed above. This is illustrated with the corrosion product in Figure 8, for position 9 o'clock (i.e. $270{ }^{\circ}$ from the windward side), which is similar to that on position 12 o'clock (Figure 7). The presence of a phase with a higher atomic number in the corrosion product is visible in the insert in Figure 8a. Moreover, as was observed on position 12 o'clock (cf. Figure 7), the corrosion products on position 9 o'clock also progressed into the bulk alloy through regions that outline the alloy grain boundaries, thus suggesting grain boundary attack. However, a lower thickness (approximately $150 \mu \mathrm{m}$ ) of compact corrosion product is observed on position 9 o'clock, but with a deeper $(>500 \mu \mathrm{m})$ internal attack along the grain boundaries. Microscopic investigations on position 9 o'clock also revealed the propagation of cracks through the attacked alloy grain boundaries (Figure 8b) in addition to severe disintegration within the Ni-rich porous regions.

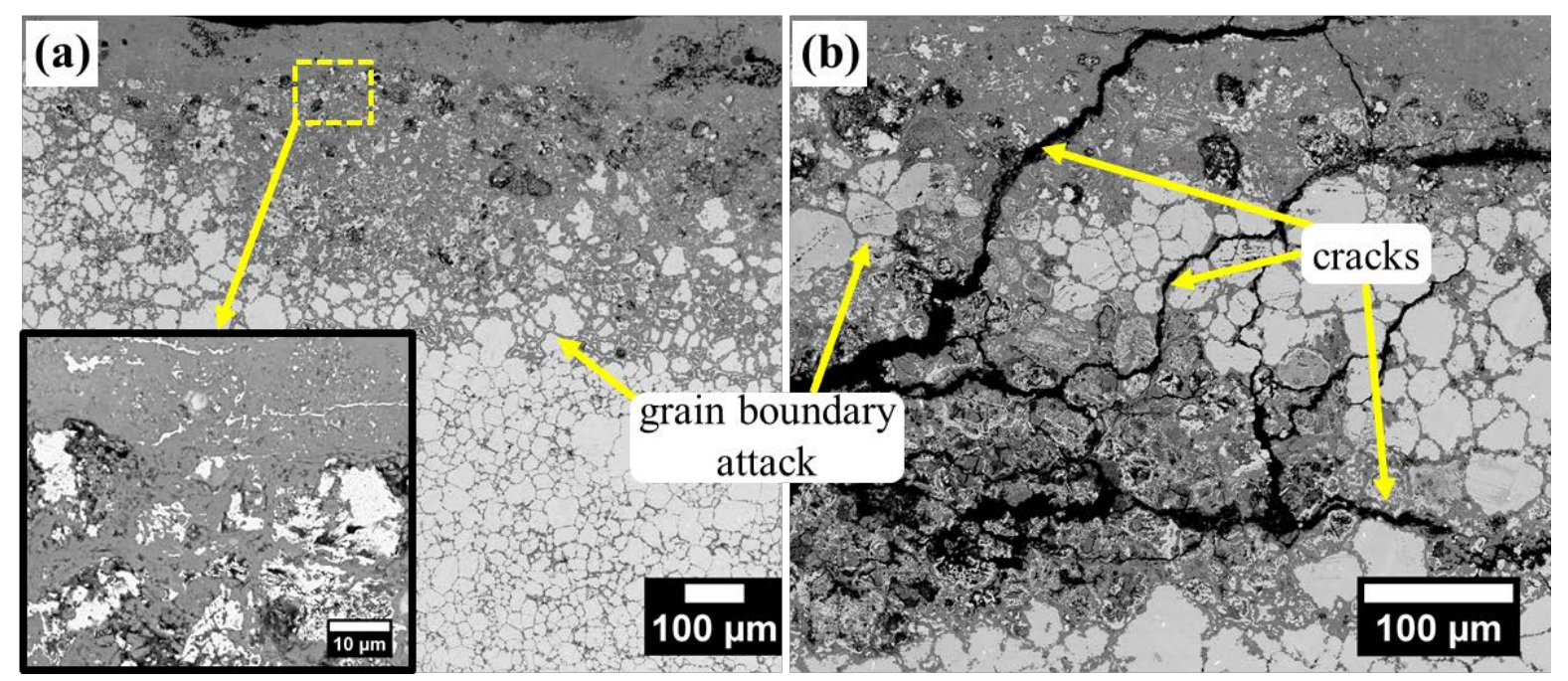

Figure 8. BSE micrographs showing: (a) an overview of the corrosion product observed on position 9 o'clock, and (b) crack propagation along the attacked alloy grain boundaries. Insert in (a) show regions with a brighter contrast attributed to the Ni-rich austenite $\left(\gamma^{\mathrm{Ni}}\right)$ phase.

\subsubsection{Compositional analysis of corrosion products}

Microstructure information on locations where both depth profiling by diffraction, and microscopic investigations were carried out was further supplemented by EDS analysis. Thus, EDS contributed to 
verification of the conclusions based on diffraction and microscopy, and revealed good agreement between the various methods.

The elemental composition of corrosion products observed on position 12 o'clock and 9 o'clock, respectively, are presented in EDS maps in Figure 9a and b. The maps show that the corrosion products comprised mainly $\mathrm{Fe}, \mathrm{Cr}$ and $\mathrm{O}$ (i.e. a Fe-Cr containing oxide). Additionally, local accumulation of $\mathrm{S}$ and $\mathrm{Cl}$ is observed in the corrosion products (although clear identification of sulphides/sulphates by energy-dispersive diffraction was difficult due to severe overlap with diffraction lines of metal oxides). EDS also indicates that $\mathrm{K}$ is present in the corrosion product. Close examination of the $\mathrm{Ni}$ and $\mathrm{O}$ maps on both positions reveal that $\mathrm{Ni}$ was incorporated in the corrosion product in a metallic form, rather than as an oxide. The metal (Ni) is scantly distributed (or absent, Figure 9b) in the near surface regions, but becomes abundantly present from the middle of the corrosion product towards the region of grain boundary attack.
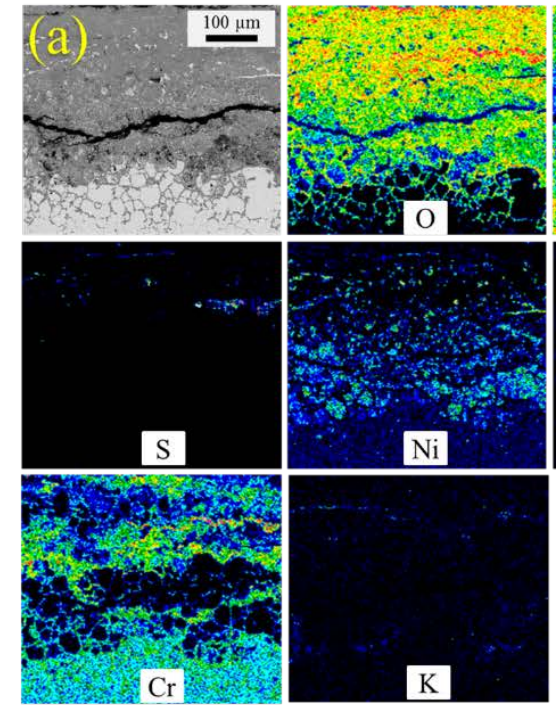
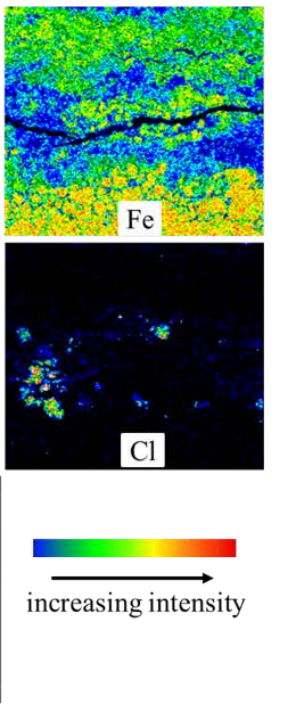

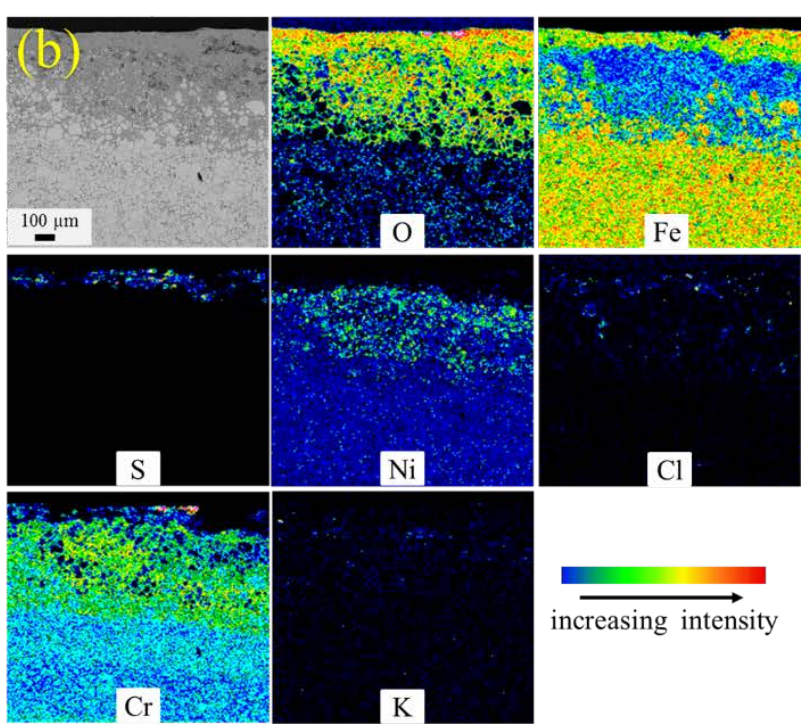

Figure 9. EDS maps showing the distribution of elements in the corrosion product observed on (a) the windward side (position 12 o'clock), (b) on the position located $270^{\circ}$ from the windward side (position 9 o’clock).

Using the elemental re-quantification method as described in section 2.3, variations in the (average) elemental concentration in the corrosion products were revealed as a function of depth (Figures 10a and b). In particular, the high averaged Ni concentration ( $28 \mathrm{wt} . \%)$ in the middle of the corrosion product (cf. Figure 10a), is in good agreement with distinct identification of diffraction lines attributed to the Ni-rich austenite $\left(\gamma^{\mathrm{Ni}}\right)$ phase on position 12 o'clock by energy-dispersive diffraction depth profiling (cf. Figure 4). In contrast, on position 9 o'clock (Figure 10b), the measured average Ni concentration is lower ( $<20 \mathrm{wt}$. \%) in the middle of the corrosion product, which explains the observed asymmetry in the $\gamma$ diffraction lines (Figure 6b) as the lattice spacing for both austenite phases is less different with reduced $\mathrm{Ni}$ content and, in addition, a lower phase fraction would also cause low intensities of the $\gamma^{\mathrm{Ni}}$ diffraction lines. 

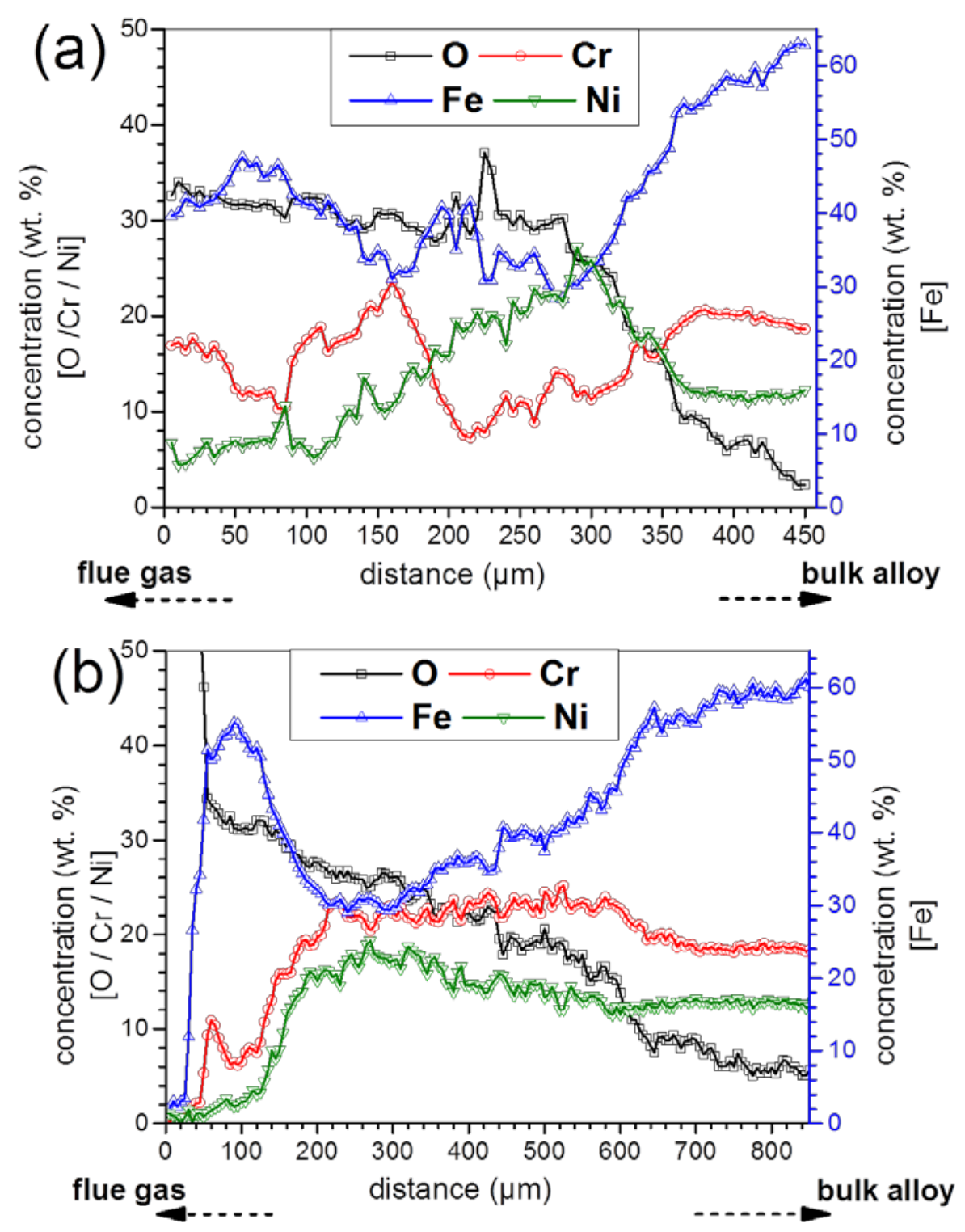

Figure 10. Depth profile of the average composition of selected elements in the corrosion product observed on (a) the windward side (position 12 o'clock) and (b) on the position located $270{ }^{\circ}$ from the windward side (position 9 o'clock) obtained through the elemental re-quantification method from the maps in Figures 8a and 8b, respectively, (note the difference in $\mathrm{x}$-axis scales).

Variations in $\mathrm{Fe}$ and $\mathrm{Cr}$ concentrations across the corrosion product follow opposing trends, and in addition, differ for the different positions investigated (Figure 10). On position 12 o'clock, the average Fe concentration increases in the near surface region (40 to $47 \mathrm{wt}$ \%), but gradually decreases to $\sim 28 \mathrm{wt}$. \% in the middle of the corrosion product before increasing to the bulk alloy value ( 62 wt. $\%)$. In contrast, the average $\mathrm{Cr}$ concentration decreases (to $10 \mathrm{wt}$. \%) in the near surface region, before a steep increase to $\sim 23 \mathrm{wt}$ \% $\%$ in the middle of the corrosion product. Afterwards, the $\mathrm{Cr}$ concentration drops to $\sim 7 \mathrm{wt}$. \% in the middle of the corrosion product before increasing to its nominal bulk alloy concentration ( 18 wt. \%). On position 9 o'clock (Figure 10b), the variation in average $\mathrm{Fe}$ and $\mathrm{Cr}$ concentrations in the near surface region is similar to that observed on position 12 
o'clock (cf. Figure 10a). However, the variation in average concentration of these elements in the middle of the corrosion product is different from the trend observed on position 12 o'clock. After a decrease to $\sim 29$ wt. \%, the average Fe concentration shows a steady increase to $\sim 55$ wt. \% before approaching the bulk alloy value ( 62 wt. \%). Concurrently, a steep increase in average $\mathrm{Cr}$ concentration from $\sim 6$ to $24 \mathrm{wt}$ \% in the middle of the corrosion product is observed. The $\mathrm{Cr}$ concentration is maintained at this value in the middle of the corrosion product before gradually decreasing to the bulk alloy value. The relationship between these trends and the changes in energy position of diffraction lines is discussed in the next section.

\section{Discussion}

Results presented in section 3 illustrate the capability of energy dispersive synchrotron diffraction in the applied transmission geometry with small gauge volume, for depth-resolved characterization of the complex and thick corrosion products observed after high temperature corrosion of superheaters during biomass-firing. Results from depth profiling by diffraction are supplemented with microscopy results by SEM and chemical element analysis by EDS. In the following subsections, these results will be discussed by first suggesting the possible corrosion mechanism and subsequently explaining how this leads to the observed variation in elemental composition within the corrosion products.

\subsection{High temperature corrosion under biomass-firing conditions and mechanism of corrosion attack}

The high content of alkali-chlorides in deposits formed during combustion of biomass in power plants is chiefly responsible for the severe corrosion attack on superheaters (see for example, [28] and the references therein). $\mathrm{KCl}$ (present in the deposit) can either react: (a) directly with the oxide of the alloying elements, $\mathrm{M}$, according to the reaction: $\mathrm{M}_{2} \mathrm{O}_{3}(\mathrm{~s})+4 \mathrm{KCl}(\mathrm{g})+2 \mathrm{H}_{2} \mathrm{O}(\mathrm{g})+\frac{3}{2} \mathrm{O}_{2}(\mathrm{~g}) \rightleftharpoons$ $2 \mathrm{~K}_{2} \mathrm{MO}_{4}(\mathrm{~s})+4 \mathrm{HCl}(\mathrm{g})$, or (b) with gaseous species in the flue gas $\left(\mathrm{SO}_{2}\right)$ in accordance with the reaction: $2 \mathrm{KCl}(\mathrm{s})+\mathrm{SO}_{2}(\mathrm{~g})+\frac{1}{2} \mathrm{O}_{2}(\mathrm{~g})+\mathrm{H}_{2} \mathrm{O} \rightleftharpoons \mathrm{K}_{2} \mathrm{SO}_{4}(\mathrm{~s})+2 \mathrm{HCl}(\mathrm{g})$, to generate Cl-bearing species $(\mathrm{HCl})$.

As the oxide forming element is consumed by reaction with $\mathrm{KCl}$ (option (a) above), the formation of a protective oxide is suppressed under biomass-firing conditions. $\mathrm{HCl}$ resulting from either of the above reactions can dissociate to produce $\mathrm{Cl}$ [29] which propagates the corrosion attack. Alternatively, direct dissociation of the $\mathrm{KCl}$ can serve as a potential source of $\mathrm{Cl}$ to propagate the corrosion attack [30]. Propagation primarily involves reaction of $\mathrm{Cl}$ (chlorination) with the alloying elements $\left(\mathrm{M}(\mathrm{s})+\mathrm{xCl} \rightleftharpoons \mathrm{MCl}_{\mathrm{x}}(\mathrm{s})\right)$. This may proceed by $\mathrm{Cl}$ transport through surfaces of cracks and pores in the corrosion product [31], oxide grain boundaries [30] or the alloy grain boundaries since they provide faster diffusion pathways. Microscopy results indicate that the corrosion attack predominantly propagated through the alloy grain boundaries (Figures 7 and 8) and, as a result, caused the severe grain boundary attack.

The thermodynamic favourability of chlorination [32] influences the selective nature of corrosion attack. Ni-rich islands and porous regions observed by microscopy (Figures 7 and 8), and high $\mathrm{Ni}$ 
concentrations observed by EDS (Figure 10) are in agreement with thermodynamic stipulations [32], and attributed to selective attack due to the higher driving force for the chlorination of $\mathrm{Fe}$ and $\mathrm{Cr}$ compared to Ni. In particular, the identification of a Ni-rich austenite phase $\gamma^{\mathrm{Ni}}$ from depth-resolved diffraction (Figure 4) can be explained by the thermodynamics on the chlorination reaction which results in selective attack of $\mathrm{Cr}$ and Fe. Similarly, the development of a Ni-rich austenite phase on the same steel due to selective Fe and $\mathrm{Cr}$ attack was also observed under controlled laboratory conditions [33]. The variation in the diffraction line positions of $\gamma^{\mathrm{Ni}}$ (Figure 5d) within the corrosion product hints at a non-linear dependence of its lattice parameter on the Ni concentration. Nonlinear variation of the lattice parameter with Ni concentration has similarly been observed in fcc Fe-Ni alloys with varying Ni contents [34].

\subsection{Oxide phase partitioning in the corrosion product}

The fate of metal chlorides formed from the chlorination reaction is dependent on their volatility as well as the oxygen partial pressure $\left(\mathrm{p}_{\mathrm{O}_{2}}\right)$ at locations where they are formed. The interplay between these factors will influence phase partition of oxides in the corrosion products which may be difficult to analyse in bulky corrosion products. Generally, the metal chloride of $\mathrm{Fe}\left(\mathrm{FeCl}_{2}\right)$ exhibits higher partial pressures than that of $\mathrm{Cr}\left(\mathrm{CrCl}_{2}\right)$ within the estimated metal temperatures of the investigated sample (below $600{ }^{\circ} \mathrm{C}$ ) [32]. Similarly, the $\mathrm{p}_{\mathrm{O}_{2}}$ required for conversion of the $\mathrm{FeCl}_{2}$ to Fe-oxides is higher than that for a similar conversion of $\mathrm{CrCl}_{2}$. It therefore follows that the corrosion product will be partitioned into Fe-oxides at the near surface regions, and $\mathrm{Cr}$-oxides close to the bulk alloy (i.e. at the corrosion front). However, analysis and comparison of results from depth-resolved diffraction analysis and EDS reveal that oxides of these elements ( $\mathrm{Fe}$ and $\mathrm{Cr}$ ) are not clearly partitioned in the corrosion product (cf. Figures 4, 5 and 10a, b). Deposit shedding is a common phenomenon occurring naturally or artificially induced in power plants, and may cause descaling of the initially formed oxides, thereby exposing the internal oxides to the corrosive atmosphere [35]. This may be responsible for the observed deviation of oxide composition from the ideal segregation into an external Fe-rich and internal Cr-rich oxide.

Alternatively, the possibility of $\mathrm{Cr}$ to be incorporated in iron oxide may cause solid solutions of CrFe-O [36,37]. Interestingly, in accordance with influencing factors stated above, depth profiling by energy-dispersive diffraction (cf. Figure 4) shows that in the near surface region, the oxide phase was a solid solution of $\mathrm{Cr}$ in the iron oxide $\mathrm{Fe}_{2} \mathrm{O}_{3}\left(\mathrm{Cr}_{\mathrm{x}} \mathrm{Fe}_{2-\mathrm{x}} \mathrm{O}_{3}\right.$, corundum) while the middle of the corrosion product consisted of a solid solution of $\mathrm{Cr}$ in $\mathrm{Fe}_{3} \mathrm{O}_{4}\left(\mathrm{FeCr}_{\mathrm{x}} \mathrm{Fe}_{2-\mathrm{x}} \mathrm{O}_{4}\right.$, spinel). Thus, a possible gradient in $\mathrm{p}_{\mathrm{O}_{2}}$ allowed formation of spinel in the middle of the corrosion product. For the corundum phase, an increase in $\mathrm{Cr}$ fraction causes a reduction in its lattice parameter $[37,38]$ and explains the slight shift of corresponding diffraction lines observed in Figure 5a. However, for the spinel phase, the effect of $\mathrm{Cr}$ fraction on the lattice parameter is not straightforward. In the Cr rich spinel ( $\mathrm{x}=2$ in $\mathrm{FeCr}_{\mathrm{x}} \mathrm{Fe}_{2-\mathrm{x}} \mathrm{O}_{4}$ ), $\mathrm{Cr}^{3+}$, due to its high octahedral stabilization energy [39-41], preferentially occupies octahedral sites, thus, preserving a normal spinel structure with $\mathrm{Fe}^{2+}$ ions in tetrahedral sites. In the Fe-rich spinel, ( $\mathrm{x}=0$ in $\mathrm{FeCr}_{\mathrm{x}} \mathrm{Fe}_{2-\mathrm{x}} \mathrm{O}_{4}$ ), structurally equivalent positions become occupied by different atoms such that $\mathrm{Fe}^{3+}$ ions are distributed between octahedral and tetrahedral sites resulting in an inversed spinel structure [42,43]. A deviation from Vegard's law follows this difference in crystal 
structure and causes a nonlinear variation of the lattice parameter from $\mathrm{Fe}_{3} \mathrm{O}_{4}$ to $\mathrm{FeCr}_{2} \mathrm{O}_{4}$ (Figure 11a) [38]. Proper elemental analysis revealing cation valences would be required to follow this effect [44], but is beyond the capability of EDS employed in this study. However, to facilitate a qualitative explanation for the shifts in energy position of the spinel diffraction lines (cf. Figures 5 and 6), the amount of $\mathrm{Cr}$ in the spinel $(\mathrm{x})$ is estimated using the relationship, $\mathrm{x}=3 \mathrm{k} /(1+\mathrm{k})$ where $\mathrm{k}=(\mathrm{Cr} / \mathrm{Fe})$ in at. \% (Figure 11b, c). This qualitative estimation (see Appendix for details) reveals that $\mathrm{x}$ varies between 0.4 and 1.3 with progression into the middle $(<\sim 200 \mu \mathrm{m})$ of the corrosion product. Such increase in $\mathrm{Cr}$ content in the $\mathrm{FeCr}_{\mathrm{x}} \mathrm{Fe}_{2-\mathrm{x}} \mathrm{O}_{4}$ system, causes an increase in lattice parameter, in accordance with values reported in [38] and [45] (Figure 11a). Interestingly, this is also in accordance with a shift to lower energies (S1 in Figures 5b and 6c) observed for the diffraction lines of the spinel phase, suggesting that a change from purely inverse, to a mixture of both inverse and normal spinel occurs when progressing towards the middle of the corrosion product [38]. For $\mathrm{x}$ values ranging from $\sim 0.6$ to $\sim 1.5$, a mixture of inverse and normal spinel is favoured [38,45], hence, the subsequent variation in $\mathrm{x}$ observed deeper in the corrosion product should not provoke significant changes in the energy position of the spinel diffraction lines. However, a further shift to higher energies (S2 in Figure 6d) observed for the spinel diffraction lines in position 9 o'clock, possibly implies that $x$ values approached a value of 2, and indicate a change from mixed spinel to the normal Cr-rich spinel $\left(\mathrm{FeCr}_{2} \mathrm{O}_{4}\right)$. This clearly highlights an under estimation of the amount of $\mathrm{Cr}$ in the spinel, at position 9 o'clock, at locations deeper in the corrosion product since the estimation does not take into account some metallic Fe rich regions present in these locations (Figure 9b). 

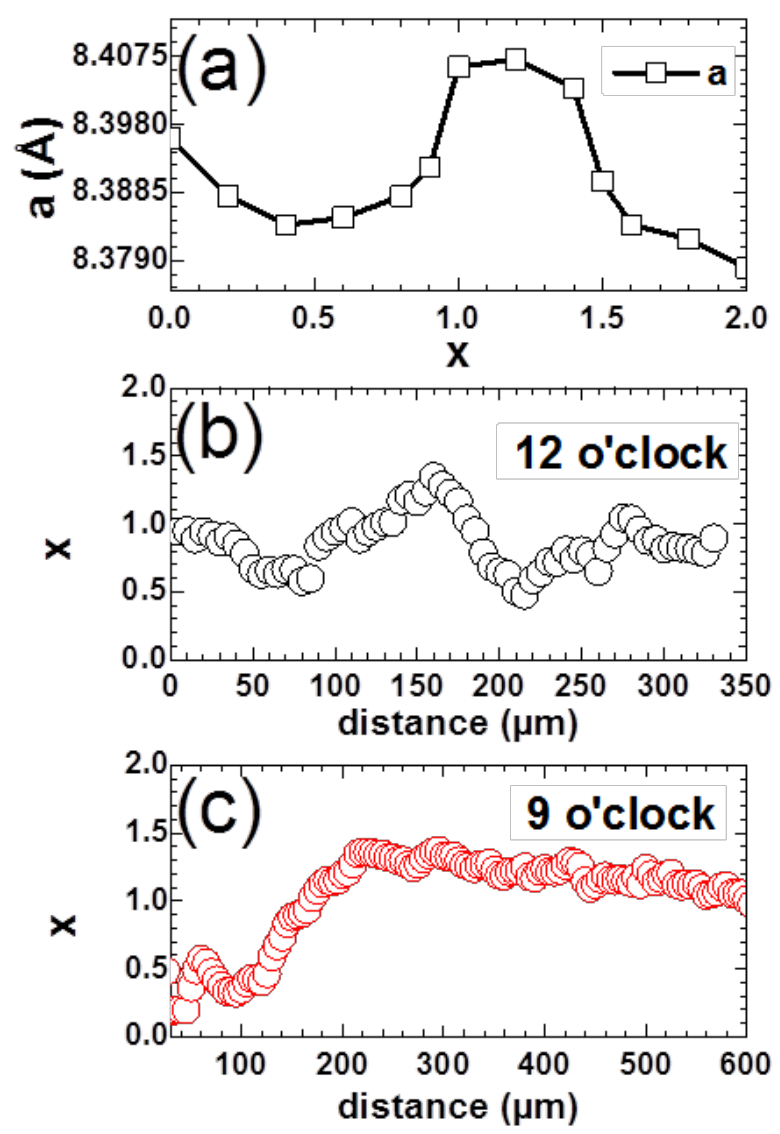

Figure 11. (a) Dependence of the lattice parameter ' $a$ ' on the $\mathrm{Cr}$ content ' $\mathrm{x}$ ' for the $\mathrm{FeCr}_{\mathrm{x}} \mathrm{Fe}_{2-\mathrm{x}} \mathrm{O}_{4}$ system according to values reported in [38]. Estimated variation of ' $x$ ' with distance in the corrosion product on (b) the windward side, 'position 12 o'clock', and (c) the position located $270{ }^{\circ}$ from the windward side, 'position 9 o'clock'.

Although the presence of stresses in the corrosion product will contribute to the observed shifts in diffraction line positions, the steep variation in chemical composition revealed by EDS suggests that the shifts are possibility due to chemical gradients in the corrosion products. This effect clearly will complicate any analysis of the stress condition in the corrosion product and was not attempted in the present study.

\section{Conclusions}

Corrosion products on a plant exposed superheater tube were studied with the complementary use of energy-dispersive synchrotron diffraction, SEM and EDS. The techniques allow for comprehensive characterization of the rather complex corrosion products resulting from biomass-firing.

By sample displacement in small steps in the $\mathrm{z}$-direction relative to a constrained gauge volume, depth profiling of corrosion product phases is feasible by means of energy dispersive synchrotron diffraction in transmission geometry. This technique reveals the predominant corrosion product phases and in addition, captures the possible effect of compositional changes on their crystallographic 
properties. In particular, the presence of a Ni-rich austenite phase resulting from the selective corrosion attack of Fe and $\mathrm{Cr}$ from the bulk alloy was clearly revealed with synchrotron diffraction depth profiling.

Corrosion products that formed on different positions on the superheater tube varied quantitatively (in terms of thickness), but not qualitatively (composition and morphology of phases). The qualitative agreement in the chemical composition, phase formation and morphology of the corrosion product along the circumference of a superheater tube, as demonstrated in the present study with the example of two locations (12 o'clock and 9 o'clock),

The corrosion product was mainly the $\mathrm{Cr}_{\mathrm{x}} \mathrm{Fe}_{2-\mathrm{x}} \mathrm{O}_{3}$ corundum phase in the near surface region, while the $\mathrm{FeCr}_{\mathrm{x}} \mathrm{Fe}_{2-\mathrm{x}} \mathrm{O}_{4}$ spinel phase dominated in larger depth of the corrosion scale. Results from all techniques agreed in revealing the presence of Ni-rich regions within the corrosion product due to KCl-induced selective attack of Fe and $\mathrm{Cr}$ from the alloy. Thus, Ni based materials may offer better corrosion resistance to biomass-induced corrosion.

Observation of severe grain boundary attack was only captured through morphological investigations with SEM, whereas diffraction analysis cannot relate detected phases to their location and local distribution within the measured volume. Therefore, it is suggested that a comprehensive characterization should involve complementary techniques, which should each be applied on the same location, as carried out in the present study.

By further supplementing both diffraction depth profiling and SEM characterisation with elemental analysis by EDS, chemical variations within phases in the corrosion product can be revealed. This approach permitted a qualitative analysis of the effect of chemical gradients on the crystal lattice parameter of spinel identified in the corrosion product and thus, may be extended for characterization of complex corrosion products in other related environments.

\section{Acknowledgements}

We acknowledge the Helmholtz-Zentrum Berlin for provision of synchrotron radiation beamtime at beamline EDDI of BESSY II and greatly acknowledge Christoph Genzel and Manuela Klaus (HZB) for their valuable technical support. Part of the synchrotron work has been supported by the European Commission under the 7th Framework Program through the 'Research Infrastructure' action of the 'Capacities' Programme, CALIPSO Grant number 312284. The project is part of the Danish Strategic Research Centre, Power Generation from Renewable Energy (GREEN) and the authors acknowledge funding from the Danish council for Strategic Research. The Danish Natural Science Research Council is also acknowledged for partly funding via Danscatt.

\section{References}

[1] F.J. Frandsen, Ash Formation, Deposition and Corrosion when Utilizing Straw for Heat and Power Production, Dr. Techn. Thesis, Department of Chemical and Biochemical Engineering, Technical Univeristy of Denmark. ISBN: 9788792481405, Kongens Lyngby, 2011. 
[2] F.J. Frandsen, Utilizing biomass and waste for power production-a decade of contributing to the understanding, interpretation and analysis of deposits and corrosion products, Fuel. 84 (2005) 1277-1294.

[3] M. Montgomery, T. Vilhelmsen, S.A. Jensen, Potential high temperature corrosion problems due to co-firing of biomass and fossil fuels, Mater. Corros. 59 (2008) 783-793.

[4] S.B. Hansen, P.A. Jensen, F.J. Frandsen, H. Wu, M.S. Bashir, J. Wadenbäck, B. Sander, P. Glarborg, Deposit Probe Measurements in Large Biomass-Fired Grate Boilers and Pulverized-Fuel Boilers, Energy \& Fuels. 28 (2014) 3539-3555.

[5] J.N. Knudsen, P.A. Jensen, K. Dam-Johansen, Transformation and Release to the Gas Phase of Cl, K, and S during Combustion of Annual Biomass, Energy \& Fuels. 18 (2004) 13851399.

[6] T.R. Miles, T.R.J. Miles, L.L. Baxter, R.W. Bryers, B.M. Jenkins, L.L. Oden, Alkali Deposits Found in Biomass Power Plants. A preliminary Investigation of their Extent and Nature., 1995.

[7] K.A. Christensen, M. Stenholm, H. Livbjerg, The formation of submicron aerosol particles, $\mathrm{HCl}$ and SO2 in straw-fired boilers, J. Aerosol Sci. 29 (1998) 421-444.

[8] M. Montgomery, S.A. Jensen, U. Borg, O. Biede, T. Vilhelmsen, Experiences with high temperature corrosion at straw-firing power plants in Denmark, Mater. Corros. 62 (2011) 593-605.

[9] T. Jonsson, N. Folkeson, M. Halvarsson, J.-E. Svensson, L.-G. Johansson, Microstructural Investigation of the HCl-Induced Corrosion of the Austenitic Alloy 310S (52Fe26Cr19Ni) at $500{ }^{\circ} \mathrm{C}$, Oxid. Met. 81 (2014) 575-596.

[10] N. Israelsson, K. Hellström, J.-E. Svensson, L.-G. Johansson, KCl-Induced Corrosion of the FeCrAl Alloy Kanthal ${ }^{\circledR}$ AF at $600{ }^{\circ} \mathrm{C}$ and the Effect of H2O, Oxid. Met. 83 (2015) 1-27.

[11] J. Sui, J. Lehmusto, M. Bergelin, M. Hupa, The Onset of Potassium Chloride Induced High Temperature Corrosion: A Novel Experimental Approach, Oxid. Met. 82 (2014) 437-456.

[12] T. Jonsson, N. Folkeson, J.-E. Svensson, L.-G. Johansson, M. Halvarsson, An ESEM in situ investigation of initial stages of the $\mathrm{KCl}$ induced high temperature corrosion of a $\mathrm{Fe}-2.25 \mathrm{Cr}-$ 1Mo steel at $400^{\circ} \mathrm{C}$, Corros. Sci. 53 (2011) 2233-2246.

[13] C. Liu, J.A. Little, P.J. Henderson, P. Ljung, Corrosion of TP347H FG stainless steel in a biomass fired PF utility boiler, J. Mater. Sci. 36 (2001) 1015-1026.

[14] C. Liu, J.A. Little, P.J. Henderson, P. Ljung, Corrosion of HR3C heat exchanger alloy in a biomass fired PF utility boiler, Mater. Corros. 51 (2000) 765-773.

[15] L.A. Hansen, H.P. Nielsen, F.J. Frandsen, K. Dam-Johansen, S. Hørlyck, A. Karlsson, Influence of deposit formation on corrosion at a straw-fired boiler, Fuel Process. Technol. 64 (2000) 189-209.

[16] M. Montgomery, A. Karlsson, O.H. Larsen, Field test corrosion experiments in Denmark with biomass fuels. Part 1: Straw-firing, Mater. Corros. 53 (2002) 121-131. 
[17] M. Montgomery, A. Karlsson, In-situ corrosion investigation at Masnedø CHP plant - a straw-fired power plant, Mater. Corros. 50 (1999) 579-584.

[18] H.P. Michelsen, F.J. Frandsen, K. Dam-Johansen, O.H. Larsen, Deposition and high temperature corrosion in a 10 MW straw fired boiler, Fuel Process. Technol. 54 (1998) 95108.

[19] S.C. Okoro, M. Montgomery, F.J. Frandsen, K. Pantleon, High Temperature Corrosion under Laboratory Conditions Simulating Biomass-Firing: A Comprehensive Characterization of Corrosion Products, Energy \& Fuels. 28 (2014) 6447-6458.

[20] S. Kiamehr, K.V. Dahl, M. Montgomery, M.A.J. Somers, KCl-induced high temperature corrosion of selected commercial alloys. Part I: chromia-formers, Mater. Corros. 66 (2015) 1414-1429.

[21] C. Genzel, I.A. Denks, J. Gibmeier, M. Klaus, G. Wagener, The materials science synchrotron beamline EDDI for energy-dispersive diffraction analysis, Nucl. Instruments Methods Phys. Res. Sect. A Accel. Spectrometers, Detect. Assoc. Equip. 578 (2007) 23-33.

[22] C. Genzel, S. Krahmer, M. Klaus, I.A. Denks, Energy-dispersive diffraction stress analysis under laboratory and synchrotron conditions: a comparative study, J. Appl. Crystallogr. 44 (2010) 1-12.

[23] R.S. Coelho, M. Klaus, C. Genzel, Through-thickness texture profiling by energy dispersive synchrotron diffraction, J. Appl. Crystallogr. 43 (2010) 1322-1328.

[24] C. Genzel, I.A. Denks, M. Klaus, The Materials Science Beamline EDDI for EnergyDispersive Analysis of Subsurface Residual Stress Gradients, Mater. Sci. Forum. 524-525 (2006) 193-198.

[25] M. Meixner, M. Klaus, C. Genzel, Sin $2 \psi$-based residual stress gradient analysis by energydispersive synchrotron diffraction constrained by small gauge volumes. II. Experimental implementation, J. Appl. Crystallogr. 46 (2013) 619-627.

[26] B.C. Giessen, G.E. Gordon, X-ray Diffraction: New High-Speed Technique Based on X-ray Spectrography, Science (80-. ). 159 (1968) 973-975.

[27] K. V Dahl, J. Hald, A. Horsewell, Grey-scale conversion X-ray mapping by EDS of multielement and multiphase layered microstructures., J. Microsc. 225 (2007) 31-40.

[28] R.A. Antunes, M.C.L. de Oliveira, Corrosion in biomass combustion: A materials selection analysis and its interaction with corrosion mechanisms and mitigation strategies, Corros. Sci. 76 (2013) 6-26.

[29] A. Zahs, M. Spiegel, H. Grabke, The influence of alloying elements on the chlorine-induced high temperature corrosion of Fe-Cr alloys in oxidizing atmospheres, Mater. Corros. 50 (1999) 561-578.

[30] N. Folkeson, T. Jonsson, M. Halvarsson, L.-G. Johansson, J.-E. Svensson, The influence of small amounts of $\mathrm{KCl}(\mathrm{s})$ on the high temperature corrosion of a Fe-2.25Cr-1Mo steel at 400 and $500^{\circ} \mathrm{C}$, Mater. Corros. 62 (2011) 606-615. 
[31] H.J. Grabke, E. Reese, M. Spiegel, The effects of chlorides, hydrogen chloride, and sulfur dioxide in the oxidation of steels below deposits, Corros. Sci. 37 (1995) 1023-1043.

[32] R. Bender, M. Schütze, The role of alloying elements in commercial alloys for corrosion resistance in oxidizing-chloridizing atmospheres part I: Literature evaluation and thermodynamic calculations on phase stabilities, Mater. Corros. 54 (2003) 567-586.

[33] S.C. Okoro, S. Kiamehr, M. Montgomery, F.J. Frandsen, K. Pantleon, Effect of flue gas composition on deposit induced high temperature corrosion under laboratory conditions mimicking biomass firing. Part I: Exposures in oxidizing and chlorinating atmospheres, Mater. Corros. 68 (2017) 499-514.

[34] R.E. Schramm, R.P. Reed, Stacking fault energies of fcc fe-Ni alloys by x-ray diffraction line profile analysis, Metall. Trans. A. 7 (1976) 359-363.

[35] M.S. Bashir, P.A. Jensen, F. Frandsen, S. Wedel, K. Dam-Johansen, J. Wadenbäck, Suspension-Firing of Biomass. Part 2: Boiler Measurements of Ash Deposit Shedding, Energy \& Fuels. 26 (2012) 5241-5255.

[36] P. Perrot, Chromium - Iron - Oxygen Landolt-Börnstein - Group IV Physical Chemistry 11D3 (Ternary Alloy Systems), Springer Berlin Heidelberg, Berlin, Heidelberg, 2008.

[37] R.K. Di Cerbo, A.U. Seybolt, Lattice Parameters of the $\alpha$-Fe2O3 -Cr2O3 Solid Solution, J. Am. Ceram. Soc. 42 (1959) 430-431.

[38] G.C. Allen, K.R. Hallam, J.A. Jutson, X-ray diffraction studies of solid solutions of Cr-, Mn-, Fe-, Co-, and Ni-containing transition metal spinel oxides, Powder Diffr. 10 (1995) 214-220.

[39] J.D. Dunitz, L.E. Orgel, Electronic properties of transition-metal oxides-I: Distortions from cubic symmetry, J. Phys. Chem. Solids. 3 (1957) 20-29.

[40] J.D. Dunitz, L.E. Orgel, Electronic properties of transition-metal oxides-II: Cation distribution amongst octahedral and tetrahedral sites, J. Phys. Chem. Solids. 3 (1957) 318323.

[41] S.E. Ziemniak, R.A. Castelli, Immiscibility in the Fe3O4-FeCr2O4 spinel binary, J. Phys. Chem. Solids. 64 (2003) 2081-2091.

[42] T.F.W. Barth, E. Posnjak, Spinel structures: with and without variate atom equipoints, Zeitschrift Für Krist. - Cryst. Mater. 82 (1932) 325-341.

[43] E.J.W. Verwey, F. de Boer, J.H. van Santen, Cation Arrangement in Spinels, J. Chem. Phys. 16 (1948) 1091.

[44] S.E. Ziemniak, M. Hanson, Corrosion behavior of NiCrFe Alloy 600 in high temperature, hydrogenated water, Corros. Sci. 48 (2006) 498-521.

[45] H.J. Yearian, J.M. Kortright, R.H. Lagenheim, Lattice Parameters of the FeFe(2-x)CrxO4 Spinel System, J. Chem. Phys. 22 (1954) 1196. 


\section{Appendix}

The amount of $\mathrm{Cr}$ in the spinel $\mathrm{FeCr}_{\mathrm{x}} \mathrm{Fe}_{2-\mathrm{x}} \mathrm{O}_{4}$, from the measured atomic fraction of $\mathrm{Fe}$ and $\mathrm{Cr}$ by EDS analysis can be estimated as follows.

Let $\mathrm{Fe}^{\mathrm{a}}$ and $\mathrm{Fe}^{\mathrm{b}}$ represent the trivalent and divalent $\mathrm{Fe}$ ions in the spinel respectively. The mole fraction of each cation in the spinel can then be written as:

Cation $\quad \mathrm{Cr} \quad \mathrm{Fe}^{\mathrm{a}} \quad \mathrm{Fe}^{\mathrm{b}}$

Mole fraction $\quad \mathrm{x} \quad 1 \quad 2-\mathrm{x}$

Assuming the trivalent and divalent Fe ions are both accounted for in the EDS measurements, the mole fraction of the cations can be rewritten as:

Cation

$\mathrm{Cr}$

$\mathrm{Fe}^{\mathrm{a}+\mathrm{b}}$

Mole fraction

$$
\mathrm{x} \quad 3-\mathrm{x}
$$

The ratio of $\mathrm{Cr}$ ion to the total Fe ions can be defined as:

$$
\frac{\mathrm{Cr}}{\mathrm{Fe}^{\mathrm{a}+\mathrm{b}}}=\mathrm{k}=\frac{\mathrm{x}}{3-\mathrm{x}}
$$

Upon rearranging we get

$$
\mathrm{x}=\frac{3 \mathrm{k}}{1+\mathrm{k}}
$$

